\title{
Impact of Covid-19 on Iran startups at biotech, pharmaceutical, engineering and other innovative industries
}

\author{
Ismael Rezaeinejad*, and Sergey U. Chernikov \\ Peoples' Friendship University of Russia (RUDN University), Miklukho-Maklaya Street, 6, 117198 \\ Moscow, Russian Federation
}

\begin{abstract}
This research reviews Corona's spread that caused many governments to take serious actions; limitations in many aspects of society and economic life as an exogenous shock for many economic actors, especially innovative ones. This review examines an entrepreneurial ecosystem to deal with the problem facing them during the crisis and how to use them to deal with that. As a response to Corona's expansion, limitations threaten many innovative startups. Our research response first represents entrepreneurs' challenges as a result of the situation. Second, we show how entrepreneurs support their investment by considering the crisis's effects and what they do. Finally, we will provide measures that policymakers can use to help entrepreneurs who face a challenge. After reviewing the previous research on the crisis and entrepreneurship, this research investigates the main challenges of high-tech startups in a heavily sanctioned developing economy like Iran. The research shows that while the SMEs successfully use their available resources as the first response to the crisis, their growth and innovation potential are at risk. Therefore, policy measures can provide immediate help to innovation by reducing the pressures resulting from limited cash circulation and long-term actions taken by the more expanded entrepreneurship ecosystem and support it to ensure rapid recovery and growth.
\end{abstract}

\section{Introduction}

This research is an overview of the study conducted in industrial and modern countries, with the discovery of acute respiratory distress syndrome (sars) in the late 1990s and recently, with all subsequent directions. However, not all of the infections caused by the new virus are not surprising; control measures such as distance working, which are conducted to slow the spread of the Covid-19 virus, enormous pressures on large parts of a country. Most of the leading players to shape the economy admit that the current orientation is a metaphor of the black killer, a surprise, unpredictable, and severe consequences that can significantly change the political and economic situation [25].

While such events can be interpreted as an opportunity or an unprecedented limitation in many parts of the society due to the Covid-19 crisis shows the current situation as an acute

* Corresponding author: mailto:1032205254@pfur.ru 
crisis [19]. The Covid-19 created many problems on the shoulders of health systems worldwide. It has fuelled an economic crisis to limit a comprehensive volume of economic activity. Furthermore, as many of the past problems have been developed at a particular point since time and region or in a given time range have been developed, the Covid-19 disease has dramatically expanded globally. The cross-sectional measures that have suddenly been applied have unexpectedly harmed the economy [8].

Therefore, the quick response has a particular attention to the section that has been firmly ignored in the current general negotiations: Startups of innovation [13]. It seems that the majority of policy initiatives to support the economies during the Covid-19 crisis, established companies, have targeted existing industry sectors and economies and through these measures are aimed at helping the employment and continued economic activity [19]. At present, the focus is on supporting the nowadays situation, while future economic activities attract less attention [25].

However, the Startups of innovative that form future economic activity is among the most vulnerable players of any economy, even encounter creative and new responsibilities and being small, which threaten the continuation of their lives [11]. This situation is likely to worsen in critical cases. The expansion of Covid-19 leads to a decrease in the enormous potential accumulated in recent years to produce economic and possibly social value innovation.

We investigated individuals involved in an entrepreneurial ecosystem in Iran to determine their reaction to the crisis and their view of the measures taken to reduce the economic impact. When writing this paper, the Iranian government's standards to protect companies and innovations affected by the Covid-19 crisis included tax support, government support for working at short hours, improved measures in guaranteed banks, and the loans and programs offered by banks.

These loans also offer additional special support programs for Startups, such as growth loans and investment schemes, which are not explicitly created to address the Covid-19 crisis but may still be beneficial. Besides, a significant undertaking of the national aid package for large enterprises, business people, and prominent entrepreneurs is presented. However, many of these measures, such as the new loan, are not available because they can not quickly meet the traditional criteria for obtaining a loan, especially in the initial stage (they cannot promptly meet the conventional standards for getting a loan). Equally, many investors are expected to did not get profit in a reasonable timeframe.

\section{Methodology}

After reviewing the previous research on the crisis and entrepreneurship, this research investigates the main challenges of high-tech startups in a heavily sanctioned developing economy like Iran. An ever-growing startup ecosystem was shaped during the past decade. The main research question is then: "What are the main challenges faced by the Iranian startups during the coronavirus pandemic?". To answer this, we first reviewed the existing literature on the topic. Then, we investigate co-founders of startups, which experienced a monthly growth rate of more than ten percent in the past year. Afterward, the author analyzed the gathered data, and the findings are presented.

\section{Results and Discussion}




\subsection{Managing the entrepreneurial crisis of innovative startups during covid-19}

Aside from the covid-19 pandemic, the virus has also increased local economies and decreased global economies. Fear of the effects of unpredictability, the disease currently affects the world's dominant economies [5]. The limited number of studies on the flexibility in entrepreneurship and crises mainly focus on pre-crisis and skills or sources that entrepreneurs and organizations create to resist or adapt to crisis events [3].

In general, specific features of innovative startups should enable them to be better prepared than other firms to deal with the Covid-19 crisis. Innovation is a prerequisite for resilience, as innovative businesses continually face a broad range of troubles [22]. However, companies do not always recognize the real threat that a potential crisis event poses, and most startups have not been prepared for the events of the past year. We have learned from research on Hurricane Katrina's effects and its consequences that lack of preparation can have significant consequences, especially for small businesses disconnected from cash flows, lack of funds for recovery, and severe infrastructure [20].

Given that data related to the immediate effects of the crisis, Covid-19 and subsequent closure are not available in many economies. The previous researches shows that the startups face the immediate and tangible consequences of the Covid-19 prevalence, especially in sales reduction, while fixed costs remain. The combination threatens the liquidity and extendedterm survival of budding companies [2].

Besides, the founders of startups reported that the economic situation is now undesirable for innovation [16]. The main partners, customers, and investors themselves are involved in responding to the crisis and uncertainty about how the problem is developed and prevents any response.

When markets face a problem, startups have to compatible with obstacles to achieving a balanced budget that will negatively affect their subsequent growth. The startups were aware that the crisis caused by the situation could also create opportunities and threats because it causes external pressure to be adapted [3].

Startups also noted that they were suddenly forced to suddenly adjust their organizational priorities because value generation processes are changed. The supply chain is affected by this crisis. Simultaneously, some of the co-founders reported that their positions had not been affected by the problem because their jobs, despite the situation, continued to relate to this issue or because they are flexible before the crisis [12]. However, such flexibility is likely to be limited. This not only describes the organization's ability to continue functioning during a disruptive event, but the conceptual aspect of the is also intended to be used before a crisis and then deployed across it [24].

Crisis management is used to strengthen the resistance in this situation, and it is of paramount importance. Managing crisis To minimize the effects of a crisis and in case of doing well, conducted studies on crisis management in entrepreneurship research mainly measures that entrepreneurs or organizations do to mitigate the potential negative consequences of a crisis, including those involved in changes in sales, marketing, and employment practices[1].

In particular, small businesses tend to be willing and flexible, and we should expect them to show such a thing in response to the Covid-19 crisis.

Therefore, crisis management in the field of entrepreneurship has a close relationship with the concept of sustainability. Rather than offering tough and rigid processes to solve borrowers' problems, it seems appropriate for innovative strategies to accept iterative and flexible approaches such as practical logic[10]. The research findings on the earthquake of Emilia in Italy indicated that the resistant entrepreneurs were those with the resources at that time, change and opportunity, so they follow a fundamental principle and respond to how innovative solutions are used to counter the Covid-19 crisis. 
The budding companies reported that they rely heavily on communication capabilities on this basis.

Moreover, co-founders reported that by gathering funds through domestic measures and asking the government to support them, they had strengthened their financial ability. However, given the support of the government, the founders reported the lack of conformity between the support services provided by the government policies and the characteristics of their organizations; therefore, they are excluded from the policy measures because, for example, they are not payable or are supported programs, and the bureaucratic faults are more than that [8].

Therefore, the first responders who responded to the crisis have not been created to obtain immediate government support. Finally, the founders reported that their customer needs change because of the Covid-19 situation. According to the above conditions, they have been using the bricolage crisis response to solve new problems. They identify and pursue new entrepreneurial opportunities and set new directions for their companies. Nevertheless, the situation is more complicated in emerging economies; Since the pandemic is "dramatically worsening the economic outlook for emerging economies," like Iran, India, Brazil, Russia, Singapore, Turkey, and Mexico are experiencing successive waves the pandemic. As these countries prioritize improving their limited public health capabilities and have tighter mobility restrictions, most of their resources were allocated to their basic needs. Besides, the IMF is expecting the emerging world to enter a severe recession in 2021. Issues such as a significant decrease in capital inflows, fewer systematic markets, higher investment risks, and their reliance on export and tourism made these countries more susceptible than developed ones. All of the mentioned issues led to paying less attention to SMEs in general and specifically to startups in countries like Iran.

Moreover, Iranian policymakers are mostly trying to help medium-sized and large firms survive to save the national employment rate. Therefore, startups suffered more from these contextual factors of the heavily sanctioned economy. According to the data published by Iran's Statistical Research and Training Center, thirty-eight percent of the Iranian firms were inactive for at least two months in the last six months. Also, the data showed a significant drop in liquidity, human resources, and production rates of the startups in general. A considerable number of startups were shocked in the first months of the pandemic. Some of them took precautionary cuts, some froze their activities, and some halted their services. Besides, Iranian startups do not have access to international customers, and therefore their markets are generally limited to the national customers, which is a significant issue. Consequently, it seems necessary for Iranian startups to understand better and address their challenges as a preliminary stage in managing crisis as Jack Ma [the founder of Alibaba] mentions: "If I want to write a book that will be "Alibaba 1001 mistakes"." because startups could learn from each other's challenges and mistakes more than the ways they survive, as their survival depends on quite a lot of different elements.

\subsection{Economic policy responses to the constraints of covid-19}

While the crisis management at the micro-level is mainly the job of entrepreneurs itself, policymakers are asked to support entrepreneurs in their efforts to cope with crises which means that policymakers are doing crisis management at the macro level because they aim to strengthen the flexibility of jobs, including options, and to support their crisis management practices. Research has shown that areas with a pre - entrepreneurial level align exogenous strategies[9]. Its flexibility characterizes an entrepreneurial region, and entrepreneurial activity can contribute to restructuring and adaptation after the crisis [11]. Followed by hurricanes and tornadoes, such individuals are motivated to join their positions, target business, and social goals. It is very likely that after the crisis, we will see areas that deal with 
the consequences of harsh actions on a different limit and several entrepreneurial potentials. The feasibility of this will depend on how entrepreneurs are innovations [22].

From the policymakers' perspective, we must rely solely on the entrepreneurial initiative to overcome the economic damage caused by limitations. Instead, it should be a key priority for policymakers in the short - term during the Covid-19 crisis to ensure that budding companies can benefit from adequate resources. External assistance for the affected areas before, during, and after limits of Covid-19 is essential.

\subsection{The Iranian startups situation}

The Iranian startup ecosystem has grown in quality and quantity in the past decade. The enterprising communities and the entire startup ecosystem have taken several steps and became more mature during this period. This evolutionary trend was well-presented in some previous studies. They have described how traditional firms have turned to startups and new technology-based firms within four decades. According to this study, the emergence of entrepreneurship in its modern sense went back to the late 1990s, followed by an ICT-based startup boom in the early 2000s. During the 2000s, entrepreneurship was expanded as an academic field, and the government introduced several initiatives.

In the $2010 \mathrm{~s}$, this trend was accelerated by all the players of the Triple Helix, i.e., universities, industries, and the government. Several leading startups, such as Snapp, Digikala, and the like, have grown dramatically and changed the whole startup ecosystem. Currently, several vital players exist at different levels, including international (e.g., international venture capitalists/venture capital funds; international startup studios, and nonresident Iranian experts and entrepreneurs), national (e.g., vice-presidency for science and technology; ministries; universities; funds; national elites foundation; Iran lab expo; national technomart of Iran; Iranian knowledge-based leaders federation; export development \& technology exchange corridor; Labs' net; the center for progress and development of Iran), industrial (e.g., innovation centers; innovation factories; sector-specific accelerators, venture capital funds, and incubators), firm (e.g., new technology-based firms (NTBFs)- knowledgebased firms; startups; creative firms), the team (e.g., independent and supported teams), and individual (e.g., freelancers; intended/potential entrepreneurs; young talented individuals) players. However, as mentioned previously, the Iranian entrepreneurial ecosystem has changed dramatically after the coronavirus pandemic. The number of failed startups has increased. There have been limited options for startups to fund their entrepreneurial journeys, such as the state-backed venture capital funds, the Vice-presidency for Science and Technology, and the National Innovation Fund. Moreover, some of the accelerators offered customized services, which led to a limited number of success stories, most of which dealt with health-related solutions.

\subsection{Iranian startups challenges}

Startups generally face several types of challenges in both local and global economies: On the one hand, several indigenous and exogenous factors could turn into challenges for startups. On the other hand, the coronavirus pandemic has already affected the national and global economies [7].

Both developing and developed economies are still suffering from such a crisis and are forecasting new types of recession. Issues such as threatening their performance and highly turbulent economic situations made these entities more vulnerable during such a global crisis [13]. Therefore, problem management has become a critical issue to be taken into account by startups. For managing such a crisis, startups should get prepared. To do so, they must know where they stand before choosing which actions to take or how to go [21]. Thus, 
understanding their challenges has become mandatory for these innovative entities. Nevertheless, just a few recent studies have already published in this domain, most of which were investigating the challenges in the world's top economies, such as Germany (e.g., see Maritz et al. 2020; Kuckertz et al. 2020), and a few studies have previously investigated the challenges faced by startups in emerging economies like Iran. Based on the mentioned above issues, we categorized these challenges into two groups: (1) general challenges and (2) crisisrelated challenges.

\subsubsection{General challenges of Iranian startups}

These challenges are a function of the business environment's general conditions [15]. For instance, according to previous studies, Iranian startups faced difficulties related to financial issues, human resources, and support mechanisms. They considered a lack of access to various types of financing, such as IPOs, bank credits, venture capital funds, and seed finance, as the most critical financial challenges of startups.

Hopefully, during the last five years, the situation has improved dramatically, and only the possibility of IPO has remained a financial challenge. It is noteworthy that the government has recently announced that five leading startups will be entered into the Tehran Stock Exchange until 2021. As a human resources management issue, the lack of team management skills remained a challenge for Iranian startups. This might be due to the country's cultural aspects, called the "Land of Individual Achievers." In the last category, the ecosystem still lacks enough support for securing intellectual property rights. Another study highlighted the government's challenges and mentioned that lack of knowledge about startup activities has led to the enactment of irrelevant rules and regulations. Generally, this was a significant issue and still is in some domains.

Nevertheless, we witnessed that the Vice-presidency for Science and Technology has paved the way for startups to grow more quickly by removing irrelevant rules and regulations and dedicating special offices for handling their insurance and tax-related concerns. Moreover, it conducted a gap analysis to measure the challenges of ICT-based startups in Iran. According to the study, startups have legal and infrastructural problems. In sum, a few studies have already paid attention to the general challenges of Iranian startups.

\subsubsection{Crisis-related challenges of Iranian startups}

The few studies on the challenges of startups in emerging economies such as Iran have mainly focused on the pre-crisis period. Given that information on the immediate impact of the crises on Iranian startups is not available, the author reviewed some relevant publications. They listed the main challenges through a qualitative research design in the following sections of this manuscript.

As a highly sanctioned emerging economy, Iranian startups have faced several challenges, even before the coronavirus pandemic. For instance, as the sanctions increased, several challenges were imposed on Iran's entrepreneurial or Startup ecosystem. Iranian startups still face a series of challenges due to a lack of access to international markets, providing them with several profitable opportunities. As these sanctions were an integral part of the economy in the past four decades, the previous Global crisis did not affect Iranian SMEs and startups as much as this pandemic did. However, Issues such as the depreciation of the local currency, limited access to international funds and markets, and challenges faced by female entrepreneurs were among the most significant challenges which affected the startup ecosystem in the past decades [17].

Nevertheless, several opportunities existed exploited by startups during these crises. For example, improvements in the Blockchain and Fintech industries were outputs of the pivots 
made by Iranian startups during these crises. In sum, given the lack of data on how Iranian startups were acting during the pandemic, limited evidence exists regarding their challenges. Therefore, this study resorts to qualitative research design to shed light on those significant challenges.

\section{Conclusions}

Human life is undoubtedly more valuable than economic activity, and this study should not be termed as a critique of the measures taken to control the spread of Covid-19. We have shown how the economic crisis affects infection control actions - and, in particular, the limitation of economic activities on innovative initiatives. For example, Covid-19 threatens the innovation potential that can be sustained at regular times, and it can be claimed this was a tremor during which the Irrecoverable business models were lost. The crisis of Covid- 19 seems different. It is not just about government intervention and the support of the initiative. It identified seven factors related to inconsistency and coping strategies. However, the first step is to understand startups' response to the crisis in general, especially the dire crisis.

Future research should determine how these factors interact, and it will be interesting to decide how to use undesired outcomes to produce positive results. Entrepreneurs, who respond to the crisis, use their approach as part of their initial response to transforming the conflict resulting from the situation. Resilience accompanies the quality of the organization's response to the crisis, and it depends on the capacity to increase improvisation, harmony, flexibility, and endurance. This is also possible to ensure that creative jobs remain alive. Many entrepreneurs have their roles in encouraging the creation of changes and creating conflicts with existing resources. Studies show that the crisis can enhance new products' growth (i.e., the development of new products). Because the crises can also stimulate new opportunities, they can promote innovation and development of productions and alternative services, particularly for lifelong jobs. The Covid-19 pandemic consequences are not yet predictable, but there seem to be more opportunities. This research indicates that coping with uncertainty and failure is a standard part of a business, even if a crisis is like a pandemic. Accordingly, entrepreneurs are expected to show flexibility in response to a situation and adapt their business models. This suggests that Startups are better prepared than other economic actors for the problem. Undoubtedly, some commentators have said that the flexibility of startups and the relatively small number they work with means eliminating them from government aid programs will not substantially impact the economy. However, the complete elimination of Startup could potentially jeopardize the government's future innovation. Therefore, long-term political action, which is unlikely to be the first response to such a crisis, seems necessary. This finding is consistent with prior research suggesting that entrepreneurial responsiveness against concerns is characterized by entrepreneurial culture and knowledge diversity, which cannot be dealt with by short-term measures, but the result is consistent.

Just as the various governments' health systems present their primary ability to respond to a pandemic, the countries that created resistance entrepreneurial ecosystems will be able to resume their level of activity faster than those who cannot afford it.

The analysis shows the Startups strongly rely on their entrepreneurial ecosystem for crisis management. Therefore, policy measures can only be successful if they are successful with a broad sense of entrepreneurship. Encourage investors to fund the startups, be an excellent way to combine both short-term cash delivery to pay bills and develop future improvements.

Startups in emerging economies generally are facing a series of challenges that could affect their success or failure. Crises could also change these challenges and priorities. The coronavirus pandemic has affected almost every single building block of their evolving business models. Then, startups should be more focused on different aspects of their business 
and their connection to the business environment. In other words, startups in emerging economies face some general challenges: endogenous and exogenous.

Moreover, they might face a series of specific challenges during a crisis like a coronavirus pandemic. Although a few scholars marginally studied the first type of challenges, the second type is rarely investigated, especially in emerging economies such as Iran. Therefore, this study attempted to identify the main challenges of Iranian startups in this coronavirus pandemic. The findings of this research could be considered a cornerstone for startups to understand their real challenges better to become able to face the coronavirus pandemic and manage the impacts of the crisis on their startups. The author concluded that startups were facing six types of challenges: financial challenges, human resources management challenges, support measures and mechanisms, marketing challenges, crisis management challenges, and further challenges (Table 1).

Table 1. Implications for startups and policymakers

\begin{tabular}{|c|c|c|}
\hline Challenge & Implications for startups & Implications for policymakers \\
\hline Financial & $\begin{array}{l}\text {-Considering creative } \\
\text { fundraising techniques } \\
\text { such as crowdfunding } \\
\text { - Revising their business } \\
\text { plans according to the } \\
\text { contingencies ofthe crisis } \\
\text { - Cutting extra costs by } \\
\text { adjustingtheir business } \\
\text { models } \\
\text { - Changing their } \\
\text { priorities by focusing on } \\
\text { profitability insteadof } \\
\text { growth }\end{array}$ & $\begin{array}{l}\text { - Supporting venture capital } \\
\text { funds,accelerators, and } \\
\text { incubators } \\
\text { - Providing enough } \\
\text { resources for state-backed } \\
\text { venture capital funds } \\
\text { - Offering working capital } \\
\text { loans with lower interest rates } \\
\text { - Delivering delayed } \\
\text { payments and direct } \\
\text { payments }\end{array}$ \\
\hline Human resources and management & $\begin{array}{l}\text { - Reconfiguring their teams } \\
\text {-Their roles to cope with } \\
\text { firing extra team members } \\
\text { - Hiring new team members } \\
\text { with multiple skills and } \\
\text { abilities }\end{array}$ & $\begin{array}{l}\text { - Offering wage subsidies } \\
\text { - Supporting temporal } \\
\text { downsizing } \\
\text { - Suggesting talented } \\
\text { memberslisted in } \\
\text { databases such as the } \\
\text { National Elites } \\
\text { Organization }\end{array}$ \\
\hline
\end{tabular}




\begin{tabular}{|c|c|c|}
\hline Support measures and mechanisms & $\begin{array}{l}\text { - Preparing different } \\
\text { ace the support mechanisms } \\
\text { - Gathering information about } \\
\text { the governmental initiatives } \\
\text { and applying for the most } \\
\text { relevant ones } \\
\text { - Receiving legal } \\
\text { consultancy services } \\
\text { about discontinued or } \\
\text { canceled contracts }\end{array}$ & $\begin{array}{l}\text { - Providing rescue } \\
\text { packages for support } \\
\text { mechanisms } \\
\text { - Considering motivating } \\
\text { policies such as tax } \\
\text { exemptions for investors } \\
\text { - Providing information } \\
\text { about governmental } \\
\text { initiatives and offering } \\
\text { support services } \\
\text { - Providing legal } \\
\text { services to help } \\
\text { startups }\end{array}$ \\
\hline $\begin{array}{l}\text { Market and marketing } \\
\text { changes }\end{array}$ & $\begin{array}{l}\text {-Revising their } \\
\text { marketing plans } \\
\text { - Considering creative } \\
\text { marketing tools and } \\
\text { techniques }\end{array}$ & $\begin{array}{l}\text { - Providing relevant } \\
\text { information about } \\
\text { markets, e.g., through } \\
\text { preparing databases } \\
\text { - Devising relevant } \\
\text { policies regarding the } \\
\text { market failures } \\
\text { - Offering creative } \\
\text { thinking and marketing } \\
\text { programs }\end{array}$ \\
\hline
\end{tabular}

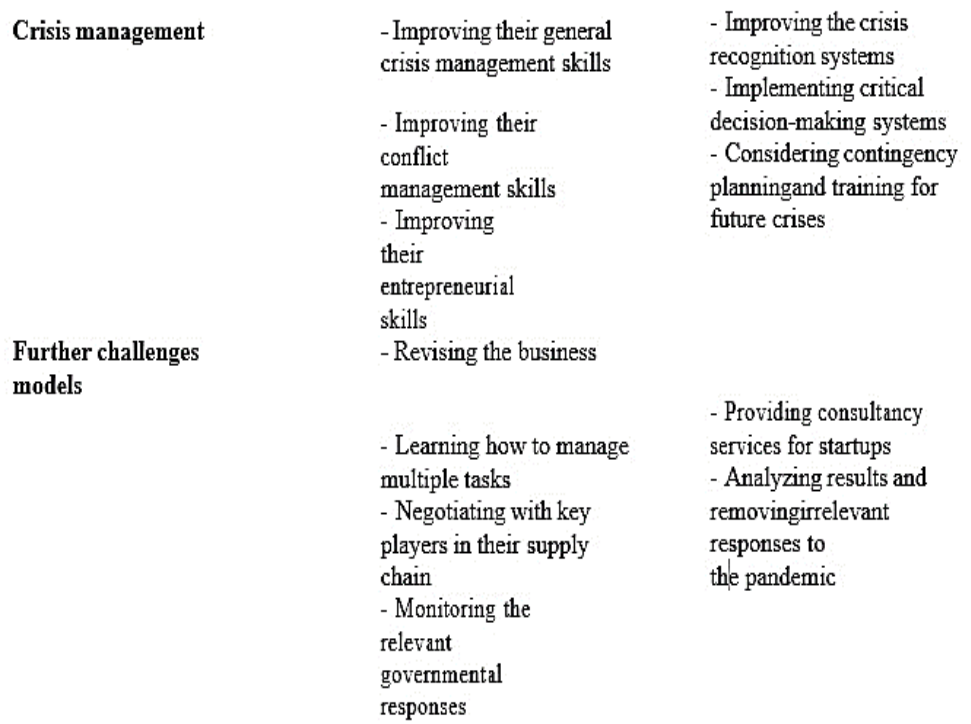

\subsection{Proposals}

There are important issues due to the studies and reviews related to entrepreneurship and crisis, especially for the startups; the international press has shown many opportunities to protect beginners' innovation potential. Although it is not clear that specific measures have the most significant impact, the programs that specifically target innovation must be forced. It is an error that policymakers have to avoid, assuming that actions are also aimed at putting SMEs out of innovative projects. Unlike many other crises, and the Covid-19 crisis has not harmed all countries at the same time. Many European countries learned from China and Italy's experiences and reacted favorably, at least in health care. While the long period of the economic crisis that has engaged nations may disappear in the long run, policymakers can 
see how the measures are taken to protect innovation are emerging, taking them as an appropriate way to improve the critical situation's knowledge. However, it can also be carried out to understand the effect of short response time to economic crises. It will be essential to follow the impact of actions taken during the Covid-19 crisis to prepare for future comparisons.

\section{References}

1. D. Alesch, J. Holly, E. Mittler, R. Nagy, Organizations at risk: What happens when small businesses and not-for-profits encounter natural disasters? (2001)

2. T. Baker, R. E. Nelson, Administrative Science Quarterly, 50, 329 (2005)

3. P. Bishop, Entrepreneurship \& Regional Development, 31, 496 (2019)

4. P. Bishop, D. Shilcof, Entrepreneurship \& Regional Development, 29, 215 (2017)

5. A. Boin, Review of Policy Research, 26, 367 (2009)

6. R., Brown, C. Mason, Small Business Economics, 49, 11 (2017)

7. D. A. Buchanan, D. Denyer, Int. J. of Management Reviews, 15, 205 (2013)

8. C.G. Bush, D. J. Ceru, R. Blackburn, Business Horizons, 52, 481 (2009)

9. M. Cowling, W. Liu, A. Ledger, Int. Small Business J., 30, 778 (2012)

10. R. Doern, N. Williams, T. Vorley, Entrepreneurship \& Regional Development, 31, 400 (2019)

11. GDA (Global Data Analysis), Coronavirus (COVID-19) Executive Briefing, Global Data (2020)

12. R. J. Glass, L. M Glass, W. E. Beyeler, H. J. Min, Emerging Infectious Diseases, 12, 1671 (2006)

13. L. E. Grube, V. H Storr, Entrepreneurship and Regional Development, 30, 800 (2018)

14. B. Herbane, Int. Small Business J., 28, 43 (2010)

15. JHCRC (Johns Hopkins Coronavirus Resource Center), Coronavirus COVID-19 Global Cases by the Center for Systems Science and Engineering (CSSE) at Johns Hopkins University (2020)

16. A. Köhn, Management Review Quarterly, 68, 3 (2008)

17. S. Korber, R. B. McNaughton, Int. J. of Entrepreneurial Behaviour \& Research, 24, 1129 (2018)

18. M. K. Linnenluecke, Int. J. of Management Reviews, 19, 4 (2017)

19. PWC (PricewaterhouseCoopers GmbH), Financial support in the Covid-19 crisis factsheet for startups and SMEs (Financial support in the Covid-19 crisis - factsheet for start-ups and SMEs) (2020)

20. R. C.Runyan, J. of Contingencies and Crisis Management, 14, 12 (2006)

21. D. Smallbone, D. Deakins, M. Battisti, J. Kitching, Int. Small Business J., 30, 754 (2012)

22. J. Spillane, M. Hough, European Management J., 21, 398 (2003)

23. T. A. Williams, D. A. Gruber, K. M. Sutcliffe, D. A. Shepherd, E. Y. Zhao, Academy of Management Annals, 11, 733 (2017)

24. T. A. Williams, D. A. Shepherd, Academy of Management J., 59, 2069 (2016)

25. A. Winston, Is the COVID-19 Outbreak a Black Swan or the New Normal? MIT Sloan Management Review (2020) 
26. A. Wyns, How our responses to climate change and the coronavirus are linked (2020) 